\title{
Isolation and Identification of Heavy Metals and Antibiotics Resistant Strains from Antananarivo Dumpsite, Madagascar
}

\author{
Hanitrinisoa Harimisa Andriamafana ${ }^{1,2}$, Yves Mong', Onja Andriambeloson ${ }^{2}$, \\ Christine Ravonizafy ${ }^{2}$, Marson Raherimandimby ${ }^{1}$, Rado Rasolomampianina ${ }^{2}$,* \\ ${ }^{1}$ Department of Fundamental and Applied Biochemistry, Faculty of Sciences, University of Antananarivo, Antananarivo, Madagascar \\ ${ }^{2}$ National Center of Environmental Research, Antananarivo, Madagascar
}

\section{Email address:}

h.harimisa@gmail.com (H. H. Andriamafana), mong2011@hotmail.fr (Y. Mong), herionja@ymail.com (O. Andriambeloson), cravonizafy@yahoo.fr (C. Ravonizafy), marson_rahery@yahoo.fr (M. Raherimandimby), mampionina@yahoo.fr (R. Rasolomampianina) ${ }^{*}$ Corresponding author

\section{To cite this article:}

Hanitrinisoa Harimisa Andriamafana, Yves Mong, Onja Andriambeloson, Christine Ravonizafy, Marson Raherimandimby, Rado Rasolomampianina. Isolation and Identification of Heavy Metals and Antibiotics Resistant Strains from Antananarivo Dumpsite, Madagascar. International Journal of Microbiology and Biotechnology. Vol. 3, No. 3, 2018, pp. 71-78. doi: 10.11648/j.ijmb.20180303.12

Received: September 11, 2018; Accepted: September 21, 2018; Published: October 30, 2018

\begin{abstract}
Heavy metals contamination is now widespread in the nature. At higher concentration, heavy metals become toxic and disturb the ecosystem including soil microorganisms. To adapt to such constraints, some microorganisms have developed tolerance mechanisms. Indeed, in the environment, the resistance of microorganisms to heavy metal often promotes to antibiotic resistance. This work aims to isolate strains from soil samples collected in Andralanitra landfill, to test their tolerance to heavy metals, to identify tolerant strains and to verify their resistance to antibiotics. According to the dilution method, a total of 48 strains were obtained, 14 were isolated on PDA medium, 10 on Sabouraud agar medium, 10 strains on Mossel agar medium, 7 on AS1 medium, 5 strains on TSA medium and 2 strains with King B medium. Resistance test to heavy metals performed by the wells method showed that out of the 48 isolated strains, 26 were capable to grow in the presence of heavy metals (solution composed of copper, zinc, cadmium, chromium, nickel, lead) at different concentrations. The highest number of tolerant strains was recorded at the concentration of $100 \mathrm{mg} / \mathrm{L} \leq \mathrm{C} \leq 1000 \mathrm{mg} / \mathrm{L}$. Four (4) strains were tolerant to the heavy metals solution at a concentration between $100 \mathrm{mg} / \mathrm{L}$ and $1500 \mathrm{mg} / \mathrm{L}$. The molecular identification of these four most resistant strains by $16 \mathrm{~S}$ rDNA gene sequencing and ITS gene sequencing allowed to classify them as belonging to the genera Ochrobactrum pseudogrignonense, Arthrobacter nicotianae, Penicillium crustosum and Penicillium commune. The antibiotic sensitivity test using disc diffusion method on Mueller-Hinton agar revealed that Ochrobactrum pseudogrignonense and Penicillium commune were resistant to Trimethoprim, Arthrobacter nicotianae showed resistance to Trimethoprim and Ciprofloxacin, Penicillium crustosum was resistant to all tested antibiotics.
\end{abstract}

Keywords: Isolation, Characterization, Resistance, Heavy Metals, Antibiotics, Dumpsite, MADAGASCAR

\section{Introduction}

In the world, dumpsite is the most used method for solid waste elimination. However, it is identified as one of the major risks for groundwater contamination [1]. Without control, waste accumulation in open air increases the threat on environmental health [2]. In Madagascar, the increasing establishment of large industrial units and the mismanagement of municipal waste generate various pollutants that are dangerous for the ecosystem. Solid wastes are all accumulated and confined in the sole municipal landfill of Andralanitra without any prior treatment.

Among these wastes, heavy metals which are the major toxic compounds produced by various industrial, pose greater problem for the environment if they are not treated properly prior to their disposal [3]. They can become mobile in the contaminated soil according to their speciation and the soil 
$\mathrm{pH}$. A fraction of the total mass may therefore become available to living organisms [4]. The contamination of the soil by heavy metals causes the decrease of the biomass and the diversity of telluric microbial population. Moreover, this contamination affects their growth, their morphology, and their biochemical activities.

The microorganisms to tolerate high concentration of metals have adopted several mechanisms which are often specific to one or several types of metals $[5,6]$. The heavy metals resistance mechanisms may involve physiological adaptation or genetic structure of the microorganisms [7, 8]. Some of these mechanisms have been identified as responsible of alteration of normal cell physiology leading to development of drug resistance in microorganisms [9].

Many researchers suggested that metal exposure indirectly promotes bacteria resistance to unrelated toxic substances, particularly antibiotics [10]. Several works demonstrated a link between heavy metal resistance and antibiotic resistance [11]. For bacteria, the genes responsible of these two types of resistance are placed on the same plasmid $[12,13]$.

The purpose of the present study is to isolate microorganisms from dumpsite soil samples, to determine their resistance to different types of heavy metals, to identify tolerant strains, and to verify their resistance to antibiotics.

\section{Materials and Methods}

\subsection{Study Site}

Andralanitra landfill with a surface of 18 ha is the only existing dumpsite within the urban district of Antananarivo. It is located in the north-eastern about $9 \mathrm{~km}$ far from the town (47 $34^{\circ} 25.5^{\prime \prime} \mathrm{E}$ of longitude and $18^{\circ} 54^{\prime} 46.1^{\prime \prime S}$ of latitude). It has been used since 1966 as solid wastes dumping site for industries and households of 2200000 inhabitants [14] in Antananarivo and its surroundings. About 450 tons of wastes per day are accumulated in this site without any treatment.

\subsection{Soil Sampling}

Soil samples were collected from the study area in a sterile plastic container, kept in ambient temperature and transported to the laboratory where they were conserved at $4^{\circ} \mathrm{C}$ until use.

\subsection{Soil Analysis}

Soil analysis was performed using Rodier's method [15] for the evaluation of heavy metals. For that, $2 \mathrm{~g}$ of soil were weighed in a capsule and mixed with $4 \mathrm{~mL}$ of sodium nitrate $(100 \mathrm{~g} / \mathrm{L})$; the mixture was then dried in the oven at $110^{\circ} \mathrm{C}$. Thereafter, the capsule was placed in the muffle furnace at $450{ }^{\circ} \mathrm{C}$ for 2 hours, and left to cool. The residue was transferred into a beaker with a few milliliters of water and the capsule was rinsed with concentrated $\mathrm{HCl}$ and boiling water successively. Five milliliters $(5 \mathrm{~mL})$ of $\mathrm{HNO}_{3}$ were then added to the residue; the mixture was boiled for ten minutes and evaporated. The residue was taken up in $20 \mathrm{~mL}$ of $\mathrm{HCl}$ $(2 \mathrm{~N})$; the mixture was boiled and filtered. The filtrate was collected in a flask; beaker and filter were rinsed with $10 \mathrm{~mL}$ of $\mathrm{HCl}(2 \mathrm{~N})$ and twice with boiling water; finally the volume was adjusted. The minerals obtained were analyzed by atomic absorption spectrometry.

\subsection{Strains Isolation}

In order to obtain a large number and diversity of strains, different types of media were used for the isolation: AS1 (Antibiotic selection 1), King B, Mossel, Sabouraud agar, TSA (Trypto-casein soya agar) and PDA (Potato-Dextrose Agar).

Strains isolation was performed using the dilution method with the previously cited media. One gram of soil sample was suspended in $9 \mathrm{~mL}$ of sterile distilled water. The mixture was shaken thoroughly and a serial dilution was prepared. One milliliter of the dilutions $10^{-2}$ and $10^{-3}$ was taken and spread aseptically into the media plates cited above. Plates were then incubated at $30^{\circ} \mathrm{C}$ for 48 hours to 4 weeks [16].

\subsection{Heavy Metals Resistance Test}

The heavy metal resistance was evaluated using the wells method. Petri dishes containing Mueller-Hinton agar media were inoculated with $100 \mu \mathrm{L}$ of tested strains spore suspension $\left(10^{6} \mathrm{CFU} / \mathrm{mL}\right)$. Wells were then formed with a sterile cork borer and $50 \mu \mathrm{L}$ of heavy metals solution (copper, zinc, cadmium, chromium, nickel, lead) at different concentrations $(100,250,500,1000,1500 \mathrm{mg} / \mathrm{L})$ were poured into the wells. The diameter of inhibition zone was measured after incubation at $30^{\circ} \mathrm{C}$ for 7 days. The strains were considered resistant when the inhibition diameter was less than $7 \mathrm{~mm}$ and non-resistant when it was higher than $10 \mathrm{~mm}$ $[17,18]$.

\subsection{Molecular Identification}

Resistant isolates were subjected to molecular identification by $16 \mathrm{~S}$ rDNA gene sequencing and ITS gene sequencing. For that, pure colonies of each isolate were picked, suspended into colony lysis buffer $(10 \mathrm{mM}$ TrisCl $\mathrm{pH}$ 8, 1mM EDTA, $50 \mathrm{mMKCl}, 0.1 \%$ Tween 20) and boiled for $10 \mathrm{~min}$. The solution was then directly used for PCR using the primers pA (AGAGTTTGATCCTGGCTCAG) and $\mathrm{pH}$ (AAGGAGGTGATCCAGCCGCA) for 16S rDNA gene and ITS1 (TCCGTAGGTGAACCTGCGC) and ITS4 (TCCTCCGCTTATTGATATGC) for ITS gene. PCR products sequencing was performed by Sanger method using the primers pA and ITS1.

Sequencing products were checked and assembled with CLC Workbench program for the final sizes of $993 \mathrm{pb}$ for the isolate $\mathrm{S} 6,1048 \mathrm{pb}$ for $\mathrm{S} 9,953 \mathrm{pb}$ for $\mathrm{S} 13$ and $562 \mathrm{pb}$ for the strain S14. The sequences were compared with the genbank database available at http://www.ezbiocloud.net/identify for 16S rDNA gene and at www.mycobank.org for ITS gene

\subsection{Antibiotics Sensitivity Test}

Sensitivity test to antibiotics of heavy metals resistant isolates was performed using disk diffusion method on 
Mueller-Hinton agar media. The antibiotics used were: Cefotaxime $5 \mu \mathrm{g}$ (COX), Cefotaxime 30 $\mathrm{g}$ (CTX), Ciprofloxacine $5 \mu \mathrm{g}$ (CIP), Ketoconazole 50 $\mathrm{g}$ (KET), Sulphamethoxazole trimethoprim $25 \mu \mathrm{g}$ (SXT), Cefixime

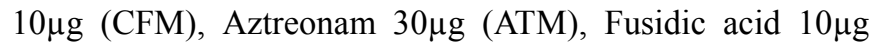

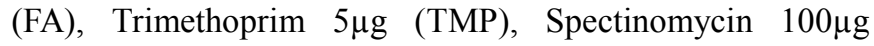
(SPT), Nalidixic acid 30 $\mu$ g (NA) and Erythromycin $15 \mu \mathrm{g}$ (ERY). Inhibition zone was noted after 48 hours of incubation at $35-37^{\circ} \mathrm{C}$. Strains were considered susceptible when the inhibition zone diameter was higher than $12 \mathrm{~mm}$ [19]. Tests were performed in duplicate and the sterility of medium plate was confirmed by incubating two plates of un-inoculated agar plate with the inoculated plates.

\section{Results}

\subsection{Soil Analysis}

The results of the soil analysis are summarized in Table 1.

Table 1. Soil analysis results.

\begin{tabular}{lll}
\hline Elements & Concentrations (mg/kg) & Reference value (AFNOR) \\
\hline Lead $(\mathrm{Pb})$ & 728.81 & 100 \\
Nickel $(\mathrm{Ni})$ & 20.00 & 50 \\
Cadmium $(\mathrm{Cd})$ & 1.36 & 2 \\
Iron $(\mathrm{Fe})$ & 7.22 & - \\
Manganese $(\mathrm{Mn})$ & 670.37 & 100 \\
Copper $(\mathrm{Cu})$ & 260.92 & 100 \\
\hline
\end{tabular}

\subsection{Strains Isolation}

A total of forty eight (48) strains were isolated from the samples collected in Andralanitra dumpsite. The strains were coded S1 to S48. Out of the 48 strains, 14 were isolated on PDA medium, 10 on Sabouraud agar medium, 10 strains on Mossel agar medium, 7 on AS1, 5 strains with TSA medium and 2 strains with King B medium (Figure 1).

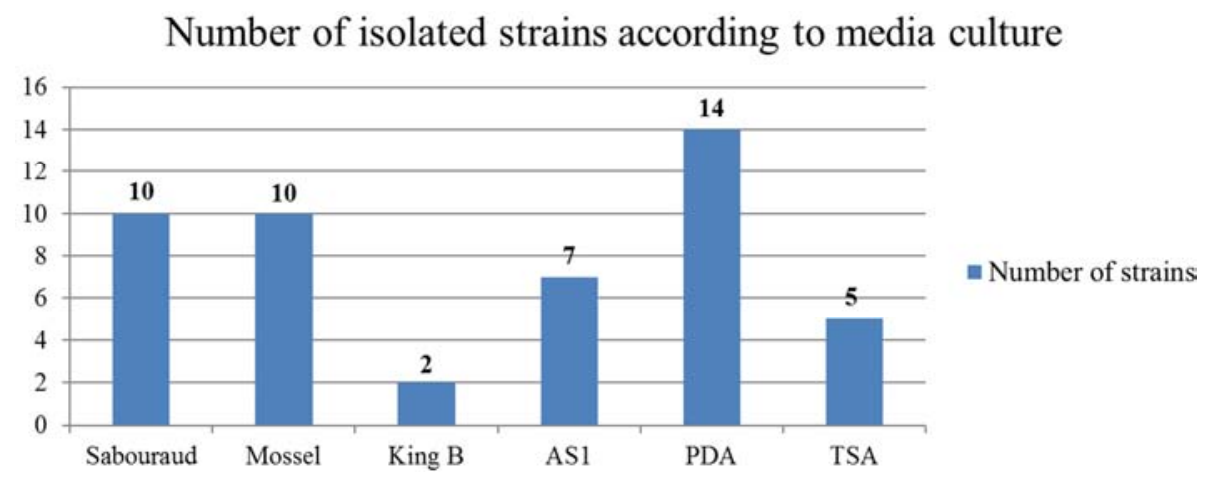

Figure 1. Number of isolated strains according to media culture.

\subsection{Heavy Metals Resistance Test}

The results of the heavy metals resistance test of isolated strains showed that among the 48 strains tested, 26 strains were tolerant to the heavy metals at different concentrations
(Figure 2, figure 3). The highest number of tolerant strains was recorded at the concentration of $100 \mathrm{mg} / \mathrm{L} \leq \mathrm{C} \leq$ $1000 \mathrm{mg} / \mathrm{L}$. Four (4) strains were tolerant to the heavy metals solution at a concentration between $100 \mathrm{mg} / \mathrm{L}$ and $1500 \mathrm{mg} / \mathrm{L}$.

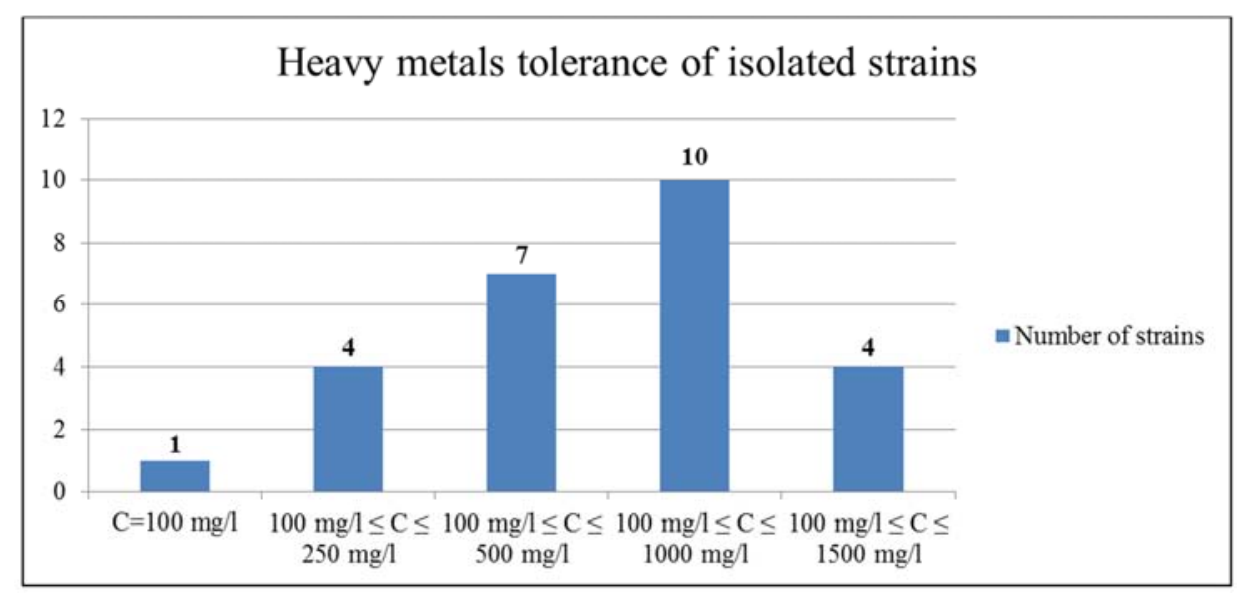

Figure 2. Heavy metals tolerance of isolated strains. 


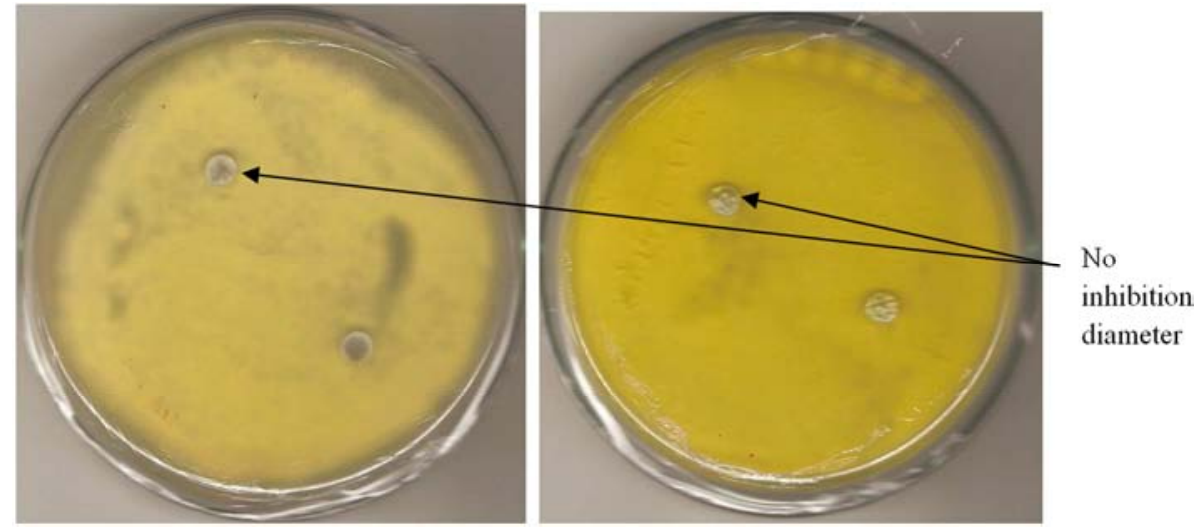

Figure 3. Resistance of strain S13 to heavy metals at concentrations of 1000 and $1500 \mathrm{mg} / \mathrm{L}$.

\subsection{Molecular Identification}

Molecular characterization using $16 \mathrm{~S}$ rRNA gene sequencing method of the two resistant isolates showed that the isolate $\mathrm{S} 6$ belongs to Ochrobactrum pseudogrignonense with $99.07 \%$ of similarity (Figure 4 ) and the isolate S9 to
Arthrobacter nicotianae with $99.90 \%$ of similarity (Figure 5). The identification of the two other strains by ITS gene sequencing showed that S13 and S14 matched with high similarity with Penicillium crustosum (Figure 6) and Penicillium commune (Figure 7).

TGCAGTCGAGCGCCCCGCAGGGGAGCGGCAGACGGGTGAGTAACGCGTGGGAAT CTACCTTTTGCTACGGAATAACTCAGGGAAACTTGTGCTAATACCGTATGTGCCCT TTTGGGGAAAGATTTATCGGCAAGAGATGAGCCCGCGTTGGATTAGCTAGTTGGT GGGGTAAAGGCCTACCAAGGCGACGATCCATAGCTGGTCTGAGAGGATGATCAGC CACACTGGGACTGAGACACGGCCCAGACTCCTACGGGAGGCAGCAGTGGGGAATA TTGGACAATGGGCGCAAGCCTGATCCAGCCATGCCGCGTGAGTGATGACGGTCTT AGGATTGTAAAGCTCTTTCACCGGTGAAGATAATGACGGTAACCGGAGAAGAAGC CCCGGCTAACTTCGTGCCAGCAGCCGCGGTAATACGAAGGGGGCTAGCGTTGTTC GGATTTACTGGGCGTAAAGCGCACGTAGGCGGACTTTTAAGTCAGGGGTGAAATC CCAGAGCTCAACTCTGGAACTGCCTTTGATACTGGAAGTCTTGAGTATGGTAGAGG TGAGTGGAATTCCGAGTGTAGAGGTGAAATTCGTAGATATTCGGAGGAACACCAG TGGCGAAGGCGGCTCACTGGACCATTACTGACGCTGAGGTGCGAAAGCGTGGGGA GCAAACAGGATTAGATACCCTGGTAGTCCACGCCGTAAACGATGAATGTTAGCCG TCGGGGTGTTTACACTTCGGTGGCGCAGCTAACGCATTAAACATTCCGCCTGGGGA GTACGGTCGCAAGATTAAAACTCAAAGGAATTGACGGGGGCCCGCACAAGCGGTG GAGCATGTGGTTTAATTCGAAGCAACGCGCAGAACCTTACCAGCCCTTGACATACC GGTCGCGGACACAGAGATGTGTCTTTCAGTTCGGCTGGACCGGATACAGGTGCTG CATGGCTGTCGTCAGCTCGTGTCGTGAGATG

Figure 4. Sequence of the 16S RNA gene of the isolate S6 (Ochrobactrum pseudogrignonense).

ATGAAGCCCAGCTTGCTGGGTGGATTAGTGGCGAACGGGTGAGTAACACGTGAGTAA CCTGCCCCCGACTCTGGGATAAGCCCGGGAAACTGGGTCTAATACCGGATATGACCT CGCACCGCATGGTGCGGGGTGGAAAGATTTATCGGTGGGGGATGGACTCGCGGCCTA TCAGCTTGTTGGTGAGGTAATGGCTCACCAAGGCGACGACGGGTAGCCGGCCTGAGA GGGTGACCGGCCACACTGGGACTGAGACACGGCCCAGACTCCTACGGGAGGCAGCA GTGGGGAATATTGCACAATGGGCGAAAGCCTGATGCAGCGACGCCGCGTGAGGGAT GACGGCCTTCGGGTTGTAAACCTCTTTCAGTAGGGAAGAAGCGAAAGTGACGGTACC TGCAGAAGAAGCGCCGGCTAACTACGTGCCAGCAGCCGCGGTAATACGTAGGGCGC AAGCGTTATCCGGATTTATTGGGCGTAAAGAGCTCGTAGGCGGTTTGTCGCGTCTGCC GTGAAAGTCCGAGGCTCAACCTCGGATCTGCGGTGGGTACGGGCAGACTAGAGTGAT GTAGGGGAGACTGGAATTCCTGGTGTAGCGGTGAAATGCGCAGATATCAGGAGGAA CACCGATGGCGAAGGCAGGTCTCTGGGCATTTACTGACGCTGAGGAGCGAAAGCATG GGGAGCGAACAGGATTAGATACCCTGGTAGTCCATGCCGTAAACGTTGGGCACTAGG TGTGGGGGACATTCCACGTTTTCCGCGCCGTAGCTAACGCATTAAGTGCCCCGCCTGG GGAGTACGGCCGCAAGGCTAAAACTCAAAGGAATTGACGGGGGCCCGCACAAGCGG CGGAGCATGCGGATTAATTTCGATGCAACGCGAAGACCTTACCAAGGCTTGACATGT GCCAGACCGCTCCAGAGATGGGGTTTCCCTTCGGGCTGGTTCACAG

Figure 5. Sequence of the 16S RNA gene of the isolate S9 (Arthrobacter nicotianae). 


\begin{abstract}
CTGGGTCCACCTCCCACCCGTGTTTATTTTACCTTGTTGCTTCGGCGGGCCCGCCTT
AACTGGCCGCCGGGGGGCTTACGCCCCCGGGCCCGCGCCCGCCGAAGACACCCTC GAACTCTGTCTGAAGATTGTAGTCTGAGTGAAAATATAAATTATTTAAAACTTTCA ACAACGGATCTCTTGGTTCCGGCATCGATGAAGAACGCAGCGAAATGCGATACGT AATGTGAATTGCAAATTCAGTGAATCATCGAGTCTTTGAACGCACATTGCGCCCCC TGGTATTCCGGGGGGCATGCCTGTCCGAGCGTCATTGCTGCCCTCAAGCACGGCTT GTGTGTTGGGCCCCGTCCTCCGATCCCGGGGGACGGGCCCGAAAGGCAGCGGCGG CACCGCGTCCGGTCCTCGAGCGTATGGGGCTTTGTCACCCGCTCTGTAGGCCCGGC CGGCGCTTGCCGATCAACCCAAATTTTTATCCAGGTTGACCTCGGATCAGGTAGGG ATACCCGCTGAACTTAAGCATATCAATAAGCGAGGAA
\end{abstract}

Figure 6. Sequence of the ITS gene of the isolate S13 (Penicillium crustosum).

\begin{abstract}
CCCCGTGTTTATTTTACCTTGTTGCTTCGGCGGGCCCGCCTTAACTGGCCGCCGGGGGG CTTACGCCCCCGGGCCCGCGCCCGCCGAAGACACCCTCGAACTCTGTCTGAAGATTGA AGTCTGAGTGAAAATATAAATTATTTAAAACTTTCAACAACGGATCTCTTGGTTCCGGC ATCGATGAAGAACGCAGCGAAATGCGATACGTAATGTGAATTGCAAATTCAGTGAAT CATCGAGTCTTTGAACGCACATTGCGCCCCCTGGTATTCCGGGGGGCATGCCTGTCCG AGCGTCATTGCTGCCCTCAAGCCCGGCTTGTGTGTTGGGCCCCGTCCCCCGATCTCCGG GGGACGGGCCCGAAAGGCAGCGGCGGCACCGCGTCCGGTCCTCGAGCGTATGGGGCT TTGTCACCCGCTCTGTAGGCCCGGCCGGCGCTTGCCGATCAACCCAAATTTTTATCCAG GTTGACCTCGGATCAGGTAGGGATACCCGCTGAACTTAAGCATATCAATAAGCGGAGG AA
\end{abstract}

Figure 7. Sequence of the ITS gene of the isolate S14 (Penicillium commune)

\subsection{Antibiotics Sensitivity Test}

Susceptibility test of the four heavy metals resistant isolates against some antibiotics revealed that Ochrobactrum pseudogrignonense and Penicillium commune are sensitive to all antibiotics except Trimethoprim. Arthrobacter nicotianae showed resistance to two antibiotics, Trimethoprim and Ciprofloxacin. Penicillium crustosum is resistant to all selected antibiotics (Table 2, figure 8, figure 9).

\title{
Antibiotic resistance pattern of isolates against 12 antibiotics
}

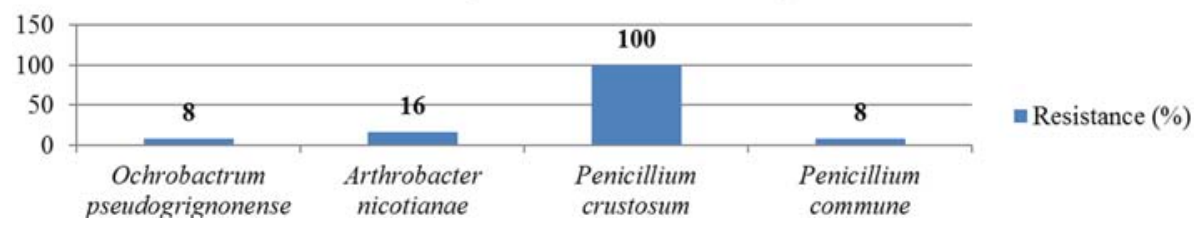

Figure 8. Antibiotic resistance pattern of isolates against 12 antibiotics.

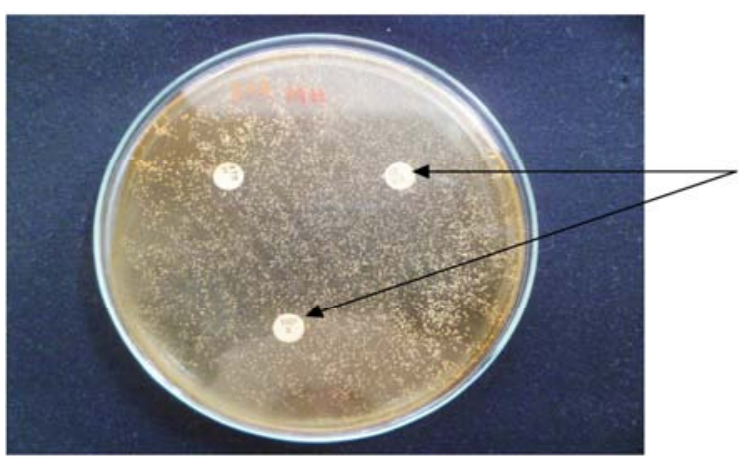

Antibiotic disc

Figure 9. Resistance of Penicillium crustosum against 3 antibiotics.

Table 2. Strains resistance to antibiotics.

\begin{tabular}{|c|c|c|c|c|c|c|}
\hline Strains & $\begin{array}{l}\text { Cefotaxime } \\
5 \mu \mathrm{g}\end{array}$ & $\begin{array}{l}\text { Cefotaxime } \\
30 \mu \mathrm{g}\end{array}$ & Ciprofloxacine $5 \mu \mathrm{g}$ & $\begin{array}{l}\text { Ketoconazole } \\
50 \mu \mathrm{g}\end{array}$ & $\begin{array}{l}\text { Sulphamethoxazole } \\
\text { trimethoprim } 25 \mu \mathrm{g}\end{array}$ & $\begin{array}{l}\text { Cefixime } \\
10 \mu \mathrm{g}\end{array}$ \\
\hline $\begin{array}{l}\text { Ochrobactrum } \\
\text { pseudogrignonense }\end{array}$ & - & - & - & - & - & - \\
\hline Arthrobacter nicotianae & - & - & $\mathrm{R}$ & - & - & - \\
\hline Penicillium crustosum & $\mathrm{R}$ & $\mathrm{R}$ & $\mathrm{R}$ & $\mathrm{R}$ & $\mathrm{R}$ & $\mathrm{R}$ \\
\hline Penicillium commune & - & - & - & - & - & - \\
\hline
\end{tabular}


Table 2. Continue.

\begin{tabular}{|c|c|c|c|c|c|c|}
\hline Strains & 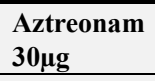 & $\begin{array}{l}\text { Fusidic } \\
\text { acid 10 } \mu \mathrm{g}\end{array}$ & Trimethoprim $5 \mu \mathrm{g}$ & $\begin{array}{l}\text { Spectinomycin } \\
100 \mu \mathrm{g}\end{array}$ & 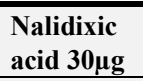 & 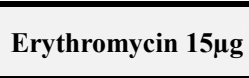 \\
\hline $\begin{array}{l}\text { Ochrobactrum } \\
\text { pseudogrignonense }\end{array}$ & - & - & $\mathrm{R}$ & - & - & - \\
\hline Arthrobacter nicotianae & - & - & $\mathrm{R}$ & - & - & - \\
\hline Penicillium crustosum & $\mathrm{R}$ & $\mathrm{R}$ & $\mathrm{R}$ & $\mathrm{R}$ & $\mathrm{R}$ & $\mathrm{R}$ \\
\hline Penicillium commune & - & - & $\mathrm{R}$ & - & - & - \\
\hline
\end{tabular}

$\mathrm{R}=$ Resistance,- = Sensitive.

\section{Discussion}

In this study, soil samples were collected in Andralanitra dumpsite and processed for strains isolation. All isolated strains were tested for heavy metals resistance, the most resistant isolates were then identified and tested for antibiotics resistance.

The soil samples analysis showed the presence of lead, nickel, cadmium, iron, manganese and copper. The lowest contaminant concentrations were recorded with cadmium and iron while the highest concentrations were noted with lead and manganese. Compared to AFNOR standards for heavy metals in soils, concentrations of lead and manganese were respectively 7 times and 6 times higher, indicating that the study site is highly polluted by these both elements.

For the isolation, a total of forty eight (48) strains were isolated from the samples using dilution method on different culture media. Previous studies showed that certain genera of microorganisms such as Citrobacter sp, Thiobacillus ferrooxidans, Bacillus cereus, Bacillus subtilis, Pseudomonas aeruginosa, Micrococcus luteus, Rhizopus arrhizus, Aspergillus flavus, Saccharomyces cerevisiae, Acinetobacter baumannii isolated from contaminated soil with heavy metals were demonstrated to be able to reduce soil pollution [20,21, 22]. Hence, the choice to use several culture media to allow the isolation of a wide variety of strains. The greatest number of isolated strains was obtained on PDA media. This could be explained by its composition, containing dextrose as a carbohydrate source which serves as a growth stimulant and potato infusion that provides a nutrient base for luxuriant growth of most fungi [23].

Heavy metals resistance test revealed that four strains were resistant to the highest concentration $(1500 \mathrm{mg} / \mathrm{L})$ of heavy metals. It was noted that the number of tolerant strains decreased as the concentration of heavy metals increased indicating, the toxic effects of metals on microorganisms [24]. Heavy metals tolerant strains play an important role in bioremediation process of contaminated soils [25]. Therefore, their isolation from polluted area constitutes the aim of many researches. Twelve (12) strains capable to grow on soil contaminated by mercury, lead, argent, zinc and copper at variable concentrations $(1,0-5,0 \mathrm{mM})$ were isolated from industrial and agricultural areas in Mauritius [26]. Ansari et al., [27] isolated from industrial soil, six strains resistant to cadmium, lead and arsenic. Our results are in accordance with Adebisi et al., [28] who isolated 26 strains from soil samples collected in Awotan-Nigéria dumpsite. Those strains were tolerant to heavy metals as lead, nickel, copper and arsenic. In bioremediation, the use of resistant strains offers many perspectives because the ability of telluric microorganisms to interact with plants allows the combination of bioremediation and phytoremediation process $[29,30]$.

The molecular identification of the four resistant strains allowed to classify them as belonging to the genera Ochrobactrum pseudogrignonense, Arthrobacter nicotianae, Penicillium crustosum and Penicillium commune. These results corroborate those found by Yang et al., [31] who demonstrated that Ochrobactrum pseudogrignonense strain can tolerate a high concentration of heavy metals. Research works conducted by Liao et al., [32] showed that other Ochrobactrum species are able to reduce chromium and other species to absorb different types of metals (lead, cadmium, zinc, copper, cobalt and nickel) [33, 34]. Some Arthrobacter species have been reported to have the ability to reduce chromium [35]. Another study conducted by Goutam et al., [36] demonstrated the effectiveness of Arthrobacter phenanthrenivorans in the bioremediation of contaminated water by heavy metals (lead, arsenic, cadmium).

Regarding fungi isolates, ubiquitous fungi can adapt to many types of substrates and they are frequently used in the bioremediation of contaminated soils and waters. Indeed, their ability to absorb heavy metals and to degrade many compounds has been shown [37]. Xu et al., [38] demonstrated the role of Penicillium chrysogenum in the detoxification and bioremediation of cadmium. Other species such as Penicilium oxalicum and Penicillium citrinium have been reported for their ability to absorb lead [39] and $P$. aurantiogriseum for biosorption of cadmium and mercury [40]. The ability of fungi to absorb heavy metals is often related to the composition of their cell walls which are rich in polysaccharides and glycoproteins (glucans, chitin, mannan and phosphomannan), these polymers provide abundant sources of ligands that can bind to metal [41].

Antibiotic susceptibility test of the four most tolerant strains showed that Ochrobactrum pseudogrignonense and Penicillium commune are resistant to one antibiotic, Arthrobacter nicotianae showed resistance to two antibiotics and Penicillium crustosum was resistant to all selected antibiotics. These results are in accordance with those of Adebisi et al., [28] who showed that all strains isolated from soil samples collected in a landfill were resistant to at least one of the tested antibiotics. The antibiotic resistance capacity of bacteria may be related to the production of enzymes that inactivate or modify antibiotics or bacteria cell 
membrane [42]. These properties are acquired when bacteria undergo genetic changes occurred during mutation or acquisition of new genetic material [43]. According to Roger et al., [44] antibiotic resistance in some bacteria is due to the transfer of resistance gene from one bacterium to another.

Penicillium species are known for their widespread occurrence and their ability to produce mycotoxins and other secondary metabolites [45]. The resistance of Penicillium crustosum to antibiotics may be explained by the production of volatile and non-volatile metabolites as penitrems, viridicatins, terrestric acid and roquefortine C [46, 47]. Penitrems and roquefortine $\mathrm{C}$ are mycotoxins produced by Penicillium species [48] and are classified as toxic compounds [49]. Viridicatin is a fungal metabolite and terrestic acid is a phytotoxic metabolite of various fungi.

Tolerance to heavy metals and antibiotics is the result of microorganisms' exposure to contaminated area by metals [50]. In terms of survival, the acquisition of these two types of resistance by the bacterium is favorable for its growth in an environment exposed to many constraints.

\section{Conclusion}

This study demonstrated the isolation of four resistant strains to heavy metals from soil samples collected in Andralanitra landfill. The strains tolerate a concentration of heavy metals of $1500 \mathrm{mg} / \mathrm{L}$ and they were identified as belonging to the genera Ochrobactrum pseudogrignonense, Arthrobacter nicotianae, Penicillium crustosum and Penicillium commune. The antibiotic resistance test revealed that Ochrobactrum pseudogrignonense and Penicillium commune were resistant to Trimethoprim, Arthrobacter nicotianae to Trimethoprim and Ciprofloxacin, and Penicillium crustosum was resistant to the 12 tested antibiotics. The accumulation of pollutants in the study area induced to the emergence of multi-resistant bacteria to heavy metals and antibiotics. As the strain S13 (Penicillium crustosum) showed the highest resistance to heavy metals and antibiotics, it could be considered as a remarkable agent for bioremediation of soils contaminated by heavy metals in our perspectives.

\section{Acknowledgements}

The authors wish to thank Professor Aurélien Carlier, Director of Laboratory of Microbiology, Ghent University, Belgium, for the molecular identification of the four heavy metals resistant strains.

\section{References}

[1] Y. Li, J. H. Li and C. Deng, Occurrence, characteristics and leakage of polybrominated diphenyl ethers in leachate from municipal solid waste landfills in China. Environ. Pollut. 184, 2014, pp: 94-100.

[2] Alexander Cogut, Open burning of waste: a global health disaster, R20 Regions of climate action, October 2016.
[3] A. Bhattacharya and A. Gupta, Evaluation of Acinetobacter sp. B9 for Cr (VI) resistance and detoxification with potential application in bioremediation of heavy-metals-rich industrial wastewater. Environmental Science and Pollution Research, volume 20, 2013, pp: 6628-6637.

[4] M. A. Ashraf, M. J. Maah and I. Yusoff Chemical speciation and potential mobility of heavy metals in the soil of former Tin mining catchment, Scientific World Journal, 2012.

[5] L. J. Piddock, Multidrug-resistance efflux pumps-not just for resistance. Nat Rev Microbiol, 2006, 4: 629-636.

[6] M. Gomathy and K. G. Sabarinathan, Microbial mechanisms of heavy metal tolerance- a review, Agric. Rev., 31 (2), 2010, pp: $133-138$.

[7] A. Malik and A. Aleem, Incidence of metal and antibiotic resistance in Pseudomonas spp from the river water, agricultural soil irrigated with waste water and ground water. Environ. Monit. Assess, 2011.

[8] T. Ntakirutimana, T. Gang Du, J. Guou, and L. Huang, Pollution and potential ecological risk assessment of heavy metals in a lake. Pol. J. Environ. Stud. Volume 22, 2013, 1129.

[9] D. Garhwal, G. Vaghela, T. Panwala, S. Revdiwala, A. Shah and S. Mulla, Lead tolerance capacity of clinical bacterial isolates and change in their antibiotic susceptibility pattern after exposure to a heavy metal. International Journal of Medicine and Public Health, 2014, 4(3): 253-256.

[10] A. O. Summers, Generally overlooked fundamentals of bacterial genetics and ecology. Clinical Infectious Diseases, 2002, 34 (Suppl 3):S85-92.

[11] Z. Yu, L. Gunn, P. Wall and S. Fanning, Antimicrobial resistance and its association with tolerance to heavy metals in agriculture production, Food microbiology, Volume 64, June 2017, pp: 23-32.

[12] J. C. Philip, R. M. Atlas, and C. J. Cunningham, Bioremediation in Nature Encyclopedia of Live Science, 2001, pp. 1-10.

[13] Don B Clewell, Antibiotic Resistance Plasmids in Bacteria, Citable reviews in the life science, February 2014.

[14] Institut National de la Statistique (INSTAT) Madagascar, 2014.

[15] J. Rodier, Analyse de l'eau, eaux naturelles, eaux résiduaires, eau de mer. 7e ed. Dunod. Paris, 1984.

[16] G. H. Holt, N. R. Krieg, P. H. A. Sneath, J. T. Staley, and S. T. Williams. Bergey's Manual of determinative Bacteriology, $9^{\text {th }}$ edition, Lippincott Williams and Wilkins, Philadelphia, 2000.

[17] S. Senthilkumar, K. Sivakumar, and L. Kannan, Mercury resistant halophilic Actinomycetes from the salt marsh environment of velar estuary, southeast coast of India. J. Aqua. Biol., 2005, 20: 141-145.

[18] A. K. Yadav, R. Kumar, R. Saikia, T. C. Bora, and D. K. Arora, Novel copper resistant and antimicrobial Streptomyces isolated from Bay of Bengal, India. J. de myc. Med., 2009, 19:234-240.

[19] F. Baquero, M. C. Negri, M. I. Morosini, and J. Blazquez, Antibiotic-selective environments. Clinical infectious Diseases, 1998, 27: S5-S11. 
[20] N. Soumitra, D. Bibhas, and S. Indu, Isolation and Characterization of Cadmium and Lead Resistant Bacteria. Global Advanced Research Journal of Microbiology, Vol. 1(11) 2012, pp: 194-198.

[21] H. E. Mohamed, Multiple heavy metal and antibiotic resistance of Acinetobacter baumannii strain HAF- 13 isolated from industrial effluents. American Journal of Microbiological Research, Vol. 4, No. 1, 2016, pp: 26-36.

[22] Q. Sadia, K. Ibrar, M. Farhana, Z. Yangguo, G. Qingbao and P. Changsheng, Isolation and characterization of heavy metal resistant fungal isolates from industrial soil in China. Pakistan journal of zoology, vol.48 (5), 2016, pp: 1241-1247.

[23] N. Rijal, Potato Dextrose Agar (PDA): principle, composition and colony characteristics. Culture Media used in Microbiology, 2015.

[24] A. Rabia, Tasneem, and A. Adam, Effect of heavy metals on soil microbial community and mung seed germination. Pak J Bot. 39, 2007. E. Abatenh, B. Gizaw, Z. Tsegaye and M. Wassie, The role of microorganisms in bioremediation- a review, Open Journal of Environmental Biology, 2017.

[25] M. Hookoom and D. Puchooa, Isolation and identification of heavy metals tolerant bacteria from industrial and agricultural areas in Mauritius, Current Research in Microbiology and Biotechnology, Vol. 1, 2013, 3: 119-123.

[26] R. A. Ansari, A. A. Qureshi, and D. S. Ramteke, Isolation and characterization of heavy-metal resistant microbes from Industrial soil, International journal of environmental sciences Volume 6, No 5, 2016.

[27] M. S. Adebisi, O. A. Oluwatosin, and T. A. Olumayowa, Resistance of bacteria isolated from Awotan dumpsite leachate to heavy metals and selected antibiotics. International Journal of Research in Pharmacy and Biosciences, Volume 2, Issue 9, October 2015, pp: 8-17.

[28] Y. Ma, R. S. Oliveira, H. Freitas and C. Zhang, Biochemical and molecular mechanisms of plant-microbe-metal intractions: relevance for phytoremediation, Frontier Plant Science, volume 7, 2016.

[29] O. B. Ojuederie and O. O. Babalola, Microbial and plantassisted bioremediation of heavy metal polluted environments: a review. International journal of environmental research and public health, volume 14, December 2017.

[30] Y. Yang, X. Yu, and R. Zhang, Draft genome sequence of Ochrobactrum pseudogrignonense strain $\mathrm{CDB} 2$, a highly efficient arsenate-resistant soil bacterium from arseniccontaminated cattle dip sites. Genome announcements, 2013. 1. $10.1128 /$ genome A. 00173-13.

[31] P. Liao et al., Chromium-resistant endophytic bacteria from Deyeuxia scabrescens (Griseb.) in Chromium contaminated area: isolation, screening and plant growth promoting. Chinese Journal of Applied \& Environmental Biology, 2015, pp: 1025-1031.

[32] X. Yu et al., Culturable Heavy Metal-Resistant and Plant Growth Promoting Bacteria in V-Ti Magnetite Mine Tailing Soil from Panzhihua, China, PloS One, volume 9, 2014.

[33] D. Ignacio et al., Cadmium biosorption properties of the metal - resistant Ochrobactrumcytisi Azn6.2. Engineering in Life Sciences Volume 10, Issue 1, 2010, pp: 49-56.

[34] D. Satarupa and A. K. Paul, In-vitro bioreduction of hexavalent chromium by viable whole cells of Arthrobacter sp. 1201, Journal of Microbiology, Biotechnology and Food Sciences, 2014, pp: 19-23.

[35] B. Goutam, K. R. Arun, P. Shubhant, and K. Ravi, An alternative approach of toxic heavy metal removal by Arthrobacter phenanthrenivorans: assessment of surfactant production and oxidative stress. Current Science, vol. 110, 2016.

[36] A. S. Ayangbenro and O. O. Babalola, A new strategy for heavy metal polluted environments: a review of microbial biosorbents, International journal of environmental research and public health, volume 14, January 2017.

[37] Xu et al., Role of Penicillium chrysogenum XJ-1 in the detoxification and bioremediation of cadmium, frontiers in Microbiology, volume 6, 2015.

[38] B. A. Oso, M. O. Olagunji and P. A. Okiki, Lead tolerance and bioadsorption potentials of indigenous soil fungi in Ado Ekiti, Nigeria. European Journal of Experimental Biology, 2015, pp: 15-19.

[39] A. Bahobil, R. A. Bayoumi, H. M. Atta and M. M. ElSehrawey, Fungal biosorption for cadmium and mercury heavy metal ions isolated from some polluted localities in KSA. International Journal of Current Microbiology and Applied Sciences, volume 6, 2017, pp: 2138-2154.

[40] B. Volesky, Biosorption and me. Water Res., 2007

[41] D. J. Kim, D. I. Lee, and J. Keller, Effect of temperature and FA on nitrification and nitrite accumulation in landfill leachate and analysis of its nitrifing bacterial community by FISH. Bioresource technology, 2006, pp: 459-468.

[42] M. Cheesbrough, District Laboratory Practice in Tropical Countries (Part II). Cambridge University, 2004, pp: 50-150.

[43] S. D. Roger, M. R. Bhave, J. F. Mercer, J. Camakaris, and B. $\mathrm{T}$. Lee, Cloning and characterization of cut $\mathrm{E}$, a gene involved in copper transport in Escherichia coli. J Bacteriol, 173, 2004, pp: 6742-6748.

[44] A. Verma, S. A. Singh, N. R. Bishnoi and A. Gupta, Biosorption of $\mathrm{Cu}$ (II) using free and immobilized biomass of Penicillium citrinum. Ecol. Eng., 61(A), 2013, pp: 486-490.

[45] J. C. Frisvad and O. Filtenborg, Terverticillate Penicillia: chemotaxonomy and mycotoxin production. Mycologia, 1989, 81: 837-861.

[46] A. A. Ismaiel, J. Papenbrock, The effects of patulin from Penicilllium vulpinum on seedling growth, root tip ultrastructure and glutathione content of maize. Eur. J. Plant Pathol. 2014, pp: 497-509.

[47] Walter and L. Sean, Acute penitrem A and roquefortine poisoning in a dog, The Canadian Veterinary Journal, 2002-5, 43:372-374.

[48] H. F. Berntsen, I. L. Bogen, M. B. Wigestrand, F. Fonnum, S. I. Walaas, A. Moldes-Anaya, The fungal neurotoxin penitrem A induces the production of reactive oxygen species in human neutrophils at submicromolarconcentration. Toxicology, 2017, 392: 64-70.

[49] H. W. $\mathrm{Hu}$ et al., Field-based evidence for copper contamination induced changes of antibiotic resistance in agicultural soils. Environ Microbiol, 2016. 